\title{
CAPÍTULO 02: RELATO DE EXPERIÊNCIA DAS AÇÕES EXTENSIONISTAS REALIZADAS EM UMA ESCOLA COMUNITÁRIA SOBRE BOAS PRÁTICAS DE FABRICAÇÃO EM TEMPOS DE PANDEMIA
}

\section{CAPÍTULO 02: INFORME DE EXPERIENCIA DE ACCIONES EXTENSIONISTAS REALIZADAS EN UNA ESCUELA COMUNITARIA SOBRE BUENAS PRÁCTICAS DE FABRICACIÓN EN TIEMPOS DE PANDEMIA}

\section{CHAPTER 02: EXPERIENCE REPORT OF EXTENSIONIST ACTIONS CARRIED OUT IN A COMMUNITY SCHOOL ON GOOD MANUFACTURING PRACTICES IN TIMES OF PANDEMIC}

\author{
João Pedro Cesário Félix ${ }^{1}$; Catherine Teixeira de Carvalho ${ }^{2}$
}

DOI: https://doi.org/10.31692/978-65-88970-18-8.21-24

\section{INTRODUÇÃO}

A extensão é uma atividade essencial para a formação acadêmica. Sem ela o aluno não é coerentemente formado. A formação para além da sala, próxima do ambiente em que o futuro profissional irá atuar, é indispensável para que este reconheça a realidade e os anseios da comunidade que cerca a instituições de ensino e possa aplicar os conhecimentos acadêmicos de forma concreta (TAFNER et al, 2015).

As Boas Práticas de Fabricação (BPF) representam uma importante ferramenta da qualidade para o alcance de níveis adequados de segurança dos alimentos. Sua adoção é um requisito da legislação vigente e faz parte dos programas de garantia da qualidade do produto final (MACHADO et al., 2015).

O projeto de extensão supracitado foi realizado na escola comunitária Nossa Senhora do Carmo que está situada no município de Bananeiras-PB. O objetivo principal do projeto foi promover as boas práticas de fabricação na escola Nossa senhora do Carmo com o foco no controle higiênico sanitário em tempos de pandemia na modalidade EAD. Teve como membros alunos e docente orientadora da Universidade Federal da Paraíba- Campus III e a participação dos servidores da escola, dentre estes: professores, merendeiras e diretores, fato este que foi primordial para a relevância e o sucesso do projeto.

\section{RELATO DE EXPERIÊNCIA}

\footnotetext{
${ }^{1}$ Graduando em Agroindústria, Universidade Federal de Paraíba, joaopedrocesariofelix@gmail.com

${ }^{2}$ Professora na Universidade Federal da Paraíba, catherine.carvalho@academico..ufpb.br
} 


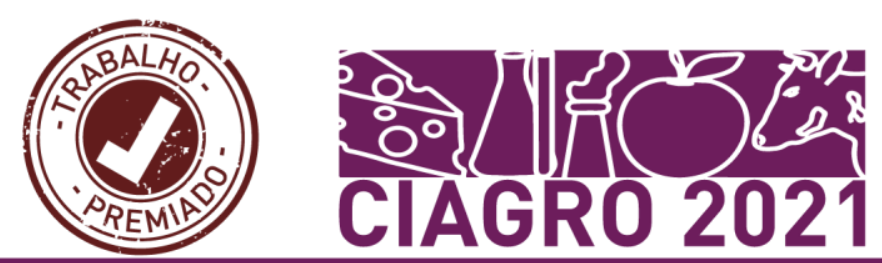

Sabe-se que a alimentação é uma necessidade básica do ser humano e o ato de se alimentar pode parecer comum, mas envolve uma série de aspectos que se relaciona com a manutenção, prevenção ou recuperação do indivíduo e assim influencia diretamente na qualidade de vida (FIGUEIREDO, VIEIRA, FONSECA, 2014). Desse modo, torna-se indiscutível a importância da alimentação saudável para a promoção da saúde, sobretudo dos organismos jovens, em fase de desenvolvimento (WORLD, 2014; SARAIVA; ZANELLA et al., 2015).

O projeto foi desenvolvido de forma remota com todos os colaboradores da escola Nossa Senhora do Carmo do município de Bananeiras-PB durante o período de maio a dezembro de 2020. O público contemplado envolveu docentes e discentes da UFPB como mediadores das ações extensionistas, os manipuladores de alimentos (merendeiras) e demais atores (funcionários e professores) vinculados à escola Nossa Senhora do Carmo como protagonistas do processo de ensino-aprendizagem.

O projeto foi executado em três etapas, a primeira etapa constituiu-se da realização de um contato prévio com a direção da escola para sensibilização e cadastramento dos funcionários interessados em participar do projeto, e para aplicação de um questionário que forneceu informações sobre o nível de conhecimento sobre as boas práticas de manipulação de alimentos (adaptado de Mello et al. (2010). Nesta etapa ainda, foi elaborado um Instagram para a divulgação do projeto com informes importantes sobre boas práticas de fabricação em tempos de pandemia e em ambiente escolar, com publicações de vários encartes animados estimulando a participação da sociedade de uma maneira geral.

Figura 01: higienizando frutas e verduras

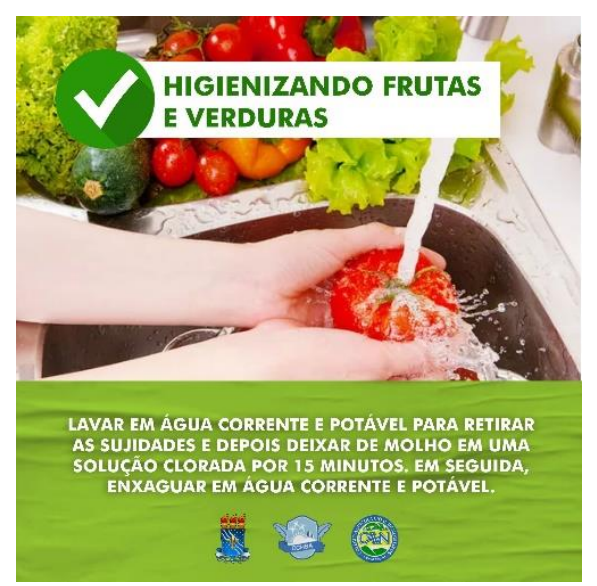

Fonte: Própria (2020)
Figura 02: Contaminação Cruzada

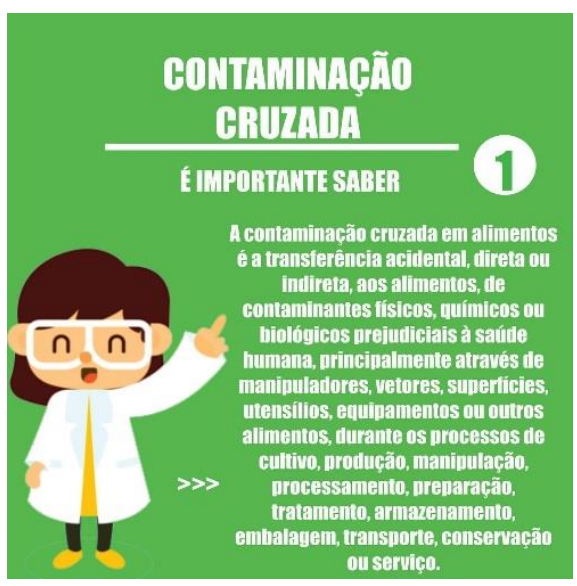

Fonte: Própria (2020)

A segunda etapa do projeto constituiu-se na criação de um grupo de estudo com todos 
os atores envolvidos no processo de aprendizagem extensionista com a elaboração e oferta de cursos de livres de curta duração em plataforma digital (YouTube) envolvendo docentes e discentes.

A terceira e última etapa compreendeu na preparação do material educativo: Cartilha informativa sobre boas práticas levando em consideração as informações obtidas nas etapas anteriores com foco em BPF no ambiente escolar em tempos de pandemia.

Figura 03: Capa da cartilha produzida

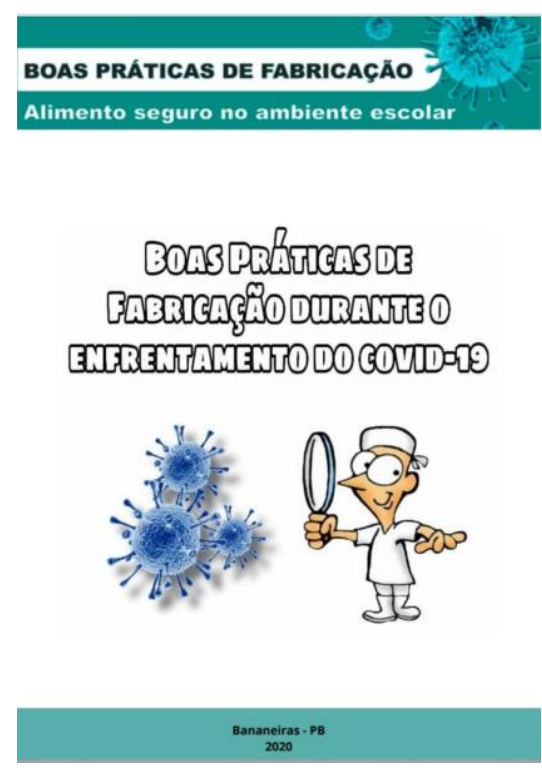

Fonte: Própria (2020)

\section{CONCLUSÕES}

A possibilidade de estabelecer contato com a comunidade externa, serviu para auxiliar de forma articulada no processo de formação de ensino aprendizagem no que diz respeito as questões de segurança alimentar. Foram adotadas estratégias como a utilização de recursos digitais remotos para promover incentivos no âmbito do ensino-aprendizagem dos atores envolvidos no projeto visando as boas práticas de manipulação de alimentos, este processo permitiu estabelecer novos campos para pesquisa, colaborando com o avanço nos estudos da agroindústria, favorecendo o campo de atuação do profissional no que concerne a produção de alimentos de qualidade e produzir alimentos seguros como um ato pedagógico ético, de compromisso social e construção coletiva de cidadania. 


\section{REFERÊNCIAS}

FIGUEIREDO, E. C.; VIEIRA, R. B.; FONSECA, K. Z. Um novo olhar sobre a capacitação de manipuladores de alimentos. Rev. Funec Cientifica - Nutrição, Santa Fé, SP, v. 2, n 3, p. 57 67, 2014.

MACHADO R.L.P.; DUTRA A.S.; PINTO M.S.V. Boas Práticas de Fabricação (BPF). Embrapa Agroindústria de Alimentos, 2015.

MELlO, A. G.; GAMA, M. P.; MARIN, V. A. COLARES, L. G. T. Conhecimento dos manipuladores de alimentos sobre boas práticas nos restaurantes públicos populares do Estado do Rio de Janeiro. Brazilian Journal of Food Technology, v. 13, n. 1, p. 60-68, 2010.

SARAIVA, D. I.; ZANARDO, V. P. S. Consumo Alimentar de Idosos com Síndrome Metabólica. In: VIII Jornada de Nutrição "Prevenção e Qualidade de Vida", 8., 2015,Erechim-RS. Anais VIII Jornada de Nutrição. Erechim-RS: URI, p. 118-137, 2015.

WORLD Health Organization: Noncommunicable Diseases (NCD) Country Profiles, 2014.

TAFNER E. P. Experiência Inovadora (EI) - Estudo de Caso Indaial - SC - 2015. 